\title{
Health and Exposure to VOCs From Pinewood in Indoor Environments
}

\section{OPEN ACCESS}

Edited by:

Liping Wang,

University of Wyoming, United States

Reviewed by:

Peder Wolkoff,

National Research Centre for the

Working Environment, Denmark

Basak Gucyeter,

Eskişehir Osmangazi University, Turkey

${ }^{*}$ Correspondence:

Knut R. Skulberg

knut.skulberg@inn.no

${ }^{\dagger}$ Present address:

Anders Q. Nyrud,

Faculty of Environmental Sciences and Natural Resource Management, Norwegian University of Life Sciences,

Ås, Norway

Armin Wisthaler

Department of Chemistry, University of Oslo, Oslo, Norway

Specialty section:

This article was submitted to Sustainable Design and Construction,

a section of the journal

Frontiers in Built Environment

Received: 15 March 2019

Accepted: 29 August 2019

Published: 12 September 2019

Citation:

Skulberg KR, Nyrud AQ, Goffeng $L O$ and Wisthaler $A$ (2019) Health and Exposure to VOCs From Pinewood in Indoor Environments.

Front. Built Environ. 5:107. doi: 10.3389/fbuil.2019.00107

\author{
Knut R. Skulberg ${ }^{1 *}$, Anders Q. Nyrud ${ }^{2 \dagger}$, Lars O. Goffeng ${ }^{3}$ and Armin Wisthaler ${ }^{4 \dagger}$ \\ ${ }^{1}$ Faculty of Social and Health Sciences, Inland Norway University of Applied Sciences, Elverum, Norway, ${ }^{2}$ Department of \\ Building and Markets, Norwegian Institute of Wood Technology, Oslo, Norway, ${ }^{3}$ Department of Occupational Medicine and \\ Epidemiology, National Institute of Occupational Health, Oslo, Norway, ${ }^{4}$ Urban Environment and Industry Department, \\ NILU - Norwegian Institute for Air Research, Kjeller, Norway
}

As a natural, biological material, wood emits various organic chemical substances, mostly volatile organic compounds (VOCs), very volatile organic compounds (VVOCs) and formaldehyde. When such emissions occur in indoor spaces, concentrations of these substances are higher than concentrations outdoors. Consequently, the level of emissions from building materials are of relevance in relation to their possible health effects. The aim of the study was to test the hypothesis that exposure to VOCs from Scots pine (Pinus sylvestris) might increase mucous membrane symptoms and/or general symptoms, compared to exposure to VOCs from Norway spruce (Picea abies). The study was carried out as a double-blinded, crossover, randomized, controlled trial. The health indicators were measured using objective and subjective methods. The VOC exposure was measured with a proton-transfer-reaction time-of-flight mass spectrometer. Thirty healthy individuals participated. The mean concentration of $\mathrm{CO}_{2}$ inside the chamber in each session varied between 420 ppm and 533 ppm. The temperature and $\mathrm{RH}$ varied between $21.5^{\circ} \mathrm{C}$ and $23.7^{\circ} \mathrm{C}$ and $12.0 \%$ and $24.2 \%$. Ozone was supplied via ventilated outdoor air. The median concentration in outdoor air was $23 \mu \mathrm{g} / \mathrm{m}^{3}$ (13 ppb). The study was conducted with a statistically significant difference in the exposure to VOCs between the experimental (pine) exposure and the control (spruce) exposure. The mean concentrations of VOCs during the experimental exposure were methanol (31 $\mathrm{ppb})$, acetaldehyde (8 ppb), formic acid (11 ppb), acetone/propanal (14 ppb), acetic acid (14 ppb) and monoterpenes (172 ppb). No difference in health outcome was revealed between the experimental and the control exposure. No inflammatory reactions or sensory irritation were found with exposure to $172 \mathrm{ppb}$ monoterpenes and a low ozone concentration. Low relative humidity may have increased eye blinking in the participants in both exposure situations.

\footnotetext{
Keywords: volatile organic compounds, scots pine, indoor environments, respiratory irritation effects, cognitive function
}

\section{INTRODUCTION}

In many cultures, wood is considered a versatile (low strength-to-weight ratio, easy to maintain, etc.) and renewable construction material. In addition, when sourced from sustainable managed forests, wood is considered a construction material with favorable environmental properties (Dodoo et al., 2009). As a natural, biological material, wood emits organic substances (volatile organic compounds (VOCs), very volatile organic compounds (VVOCs), formaldehyde and 
sometimes acrolein). When such emissions occur in indoor spaces, they result in higher concentrations than are found outdoors. As the ventilation rate (i.e., the rate of outdoor air supply to the indoor space) decreases, the magnitude of the indoor-outdoor difference in emission concentrations increases. Standards currently exist for quantifying the emissions from building materials in the indoor environment (CEN, 2017). Consequently, the levels of emissions from building materials are of relevance and several European countries have introduced national restrictions for the emission levels from building materials (ECA, 2013). In some European countries, emissions from wood are not accounted for in building regulations, because the long history of using wood indicates that the potential health hazard is negligible. This is currently about to change. Following the EU Construction Products Regulation (CPR), a European framework for threshold emission values is undergoing preparation.

Chemical agents may occur in indoor air originating from the building materials, the treatment of the materials, the furniture and cleaning, as well as consumer and personal care products. Many laboratory studies have focused on the chemical emissions from various building materials. The total amount of volatile organic compounds (TVOC) was previously used as a measurement for VOCs and as a screening tool for sensory irritation in risk assessment (Andersson et al., 1997; Mølhave, 2003), at present it is generally used as a mass metric or as a hygienic guidance value, but never as a health metric.

The emissions of VOCs are mainly terpenes from softwoods and formic acid and acetic acid from hardwoods. The most common terpenes from softwood are $\alpha$-pinene, $\beta$-pinene and $\Delta^{3}$-carene (Risholm-Sundman et al., 1998; Roffael, 2006). In general, emission levels are substantially higher from pine than from spruce. The dominant terpenes emitted from pine are $\alpha$-pinene and $\Delta^{3}$-carene (Gminski et al., 2011b). The VOC acrolein, a known respiratory toxicant, have also been detected in emissions from pine wood and indoor concentrations of acrolein can range from 2.1 to $12.2 \mu \mathrm{g} / \mathrm{m}^{3}$ (Seaman et al., 2007). The emission of terpenes from softwood declines over time; fresh wood and recently processed wood will in general have higher emissions than wood that has been stored for a period of time (Roffael, 2006). Different external factors, temperature, relative humidity $(\mathrm{RH})$, the air exchange rate, the surface area of the wood and the properties of the VOCs may also influence the indoor VOC concentration (Lin et al., 2009; Hyttinen et al., 2010; Roffael et al., 2012).

Health effects related to exposure to indoor air chemicals may occur in the eyes, upper and lower respiratory tract and heart. In addition, exposure to indoor climate chemicals can affect the nervous system, resulting in impaired concentration and attention. A number of pathways or mechanisms may be implicated in such health effects, some of which are inflammatory reactions, sensitization, sensory irritation, heart rate effects, odor reaction/effects and psychosocial stress reactions.

In a thorough review by Tagiyeva and Sheikh (2014) on asthma and allergy in relation to domestic exposure to VOCs, no firm conclusions could be drawn. In general, the studies were suggestive of possible associations between exposure and health. However, most of the studies were observational studies with inadequate measurements of exposure and inadequate adjustments for confounders. Nielsen et al. (2007) evaluated the literature on indoor chemical exposure and any adjuvant effect (allergy promoting effect). They concluded that there was little evidence for this association. In a study by Brüning et al. (2014), sensory irritation pathways in the eyes, nose and larynx/pharynx were explored, based on human and animal studies, and 19 chemical substances were identified as human irritants. Wolkoff and Nielsen (2017) evaluated the health effects of the inhalation of abundant fragrances. They reviewed four common airborne fragrances in indoor air. Maximum indoor concentrations were around odor thresholds, but much lower than the thresholds for sensory irritation in eyes and airways. Human studies indicate that health effects may be due to perception of the chemicals and work performance may be impaired by the unpleasant odor. In two experimental studies, psychosocial stress negatively influenced work performance (Fiedler et al., 2005; Pacharra et al., 2016).

It is therefore of relevance to evaluate the health effects on people of the chemical emissions from wood in the indoor environment. This issue has previously been addressed in a few studies. In an experimental study by Gminski et al. (2011b), 15 healthy participants were exposed to different levels of VOCs from pinewood. The participants were exposed for $2 \mathrm{~h}$ in a chamber. No sensory irritation of the airways or eyes and no negative effects on pulmonary function were recorded. The participants were exposed to VOC concentrations up to 13 $\mathrm{mg} / \mathrm{m}^{3}$. In another study by Gminski et al. (2011a) 24 participants were exposed to VOC concentrations up to $8.9 \mathrm{mg} / \mathrm{m}^{3}$ from oriented strand boards (OSB). The results did not reveal any sensory irritations or pulmonary effects and the sensory intensity of the exposure was rated as "neutral to pleasant." Glas et al. (2015) conducted a cross-sectional study on exposure to some indoor chemicals, including $\alpha$-pinene, together with cases of sick building syndrome. No consistent associations were found between exposure and health outcomes.

It has been shown that terpene oxidation products are formed in the reaction between terpenes and oxidants such as $\mathrm{O}_{3}, \mathrm{OH}^{\bullet}$ or $\mathrm{NO}_{3}^{\bullet}$ (Wolkoff et al., 2000; Pommer et al., 2004; Nojgaard et al., 2006). Glasius et al. (2000) studied the carboxylic acids in secondary aerosols from the oxidation of five monoterpenes, including $\alpha$-pinene and $\Delta^{3}$-carene. Carboxylic acids are more reactive than their corresponding aldehydes and may therefore play an important role in the formation of secondary organic aerosols (SOAs). The question of whether these products could cause adverse health effects on the eyes and the upper and lower respiratory airways has been a matter of scientific discussion (Wolkoff, 2013; Wells et al., 2017; Wolkoff and Nielsen, 2017).

In a workshop summary, Wells et al. (2017) reviewed health effects studies on exposure to ozone-terpene mixtures. No inflammatory reactions in the airways were observed. Sensory reactions were then found at higher concentrations than are present in normal indoor environments. In an exposure study by Fiedler et al. (2005), 130 participants were exposed to VOCs, using a mixture containing ozone and both $\alpha$-pinene and limonene. Subjective and objective data, including lung function 
and performance measurements, were obtained. No statistically significant differences in respiratory or cognitive health were revealed between the exposure groups with and without ozone. In a subsequent paper by Laumbach et al. (2005), which analyzed the symptoms and immunological markers of nasal inflammation, no statistically significant differences were found between the control exposure, VOC exposure and VOC together with ozone.

An experimental study by Satish et al. (2012) revealed adverse effects of $\mathrm{CO}_{2}$ on various tests of decision-making performance. Moderate effects were found for $\mathrm{CO}_{2}$ concentrations of 600$1,000 \mathrm{ppm}$ and large effects were found when the $\mathrm{CO}_{2}$ concentration increased to $2,500 \mathrm{ppm}$. $\mathrm{CO}_{2}$ seems to be an indoor air pollutant, however, although the authors collected subjective information on perceived air quality, this information is not presented or discussed in the study and in line with Pacharra et al. (2016) and Wolkoff and Nielsen (2017), it becomes problematic to disentangle the effects from the exposure itself from possible effects due to the perception of reduced air quality. In another experimental study by Maula et al. (2017), no substantial impacts on work performance at $\mathrm{CO}_{2}$ concentration levels of 2,260 ppm compared with performance at $540 \mathrm{ppm}$ were found. This study used the $\mathrm{CO}_{2}$ concentration levels as an indicator for bioeffluents. Allen et al. (2016) conducted an experimental study in a laboratory under different indoor air quality conditions. $\mathrm{CO}_{2}$ concentration was 500-600 ppm, 720-760 ppm, 900-970 ppm, or $1,400-1,420 \mathrm{ppm}$. The TVOC was $30-60 \mu \mathrm{g} / \mathrm{m}^{3}$ or $500-670$ $\mu \mathrm{g} / \mathrm{m}^{3}$. Tests of cognitive function were performed during the exposure. VOCs and $\mathrm{CO}_{2}$ were independently associated with the cognitive function results. Despite the double-blinded test procedure used in this study, the chosen study design cannot rule out differential odor hedonics from the various exposure conditions, as discussed by Wolkoff and Nielsen (2017) and Pacharra et al. (2016).

\section{METHODS}

The study examined responses among human participants under two different conditions in a controlled environmental chamber outfitted like an office. The aim of the study was to test the hypothesis that exposure to VOCs from pine might increase mucous membrane symptoms and/or general symptoms compared to exposure to VOCs from spruce.

\section{Study Design}

This study was a randomized, double-blinded, crossover experimental study. It had an $\mathrm{AB} / \mathrm{BA}$ design with two periods and two treatments (Scheiner and Gurevitch, 2001). The experimental treatment was exposure to VOCs from Scots pine (Pinus sylvestris), while the control treatment consisted of exposure to VOCs from Norway spruce (Picea abies) at substantially lower TVOC levels. The low TVOC loads were well-below the benchmark level in national and proposed international standards (CEN, 2017), whereas the TVOC load from the experimental setting with pine was higher than international standards.

The exposure time was $2 \mathrm{~h}$ in both settings and there was a gap of at least seven days and at most 10 days between the

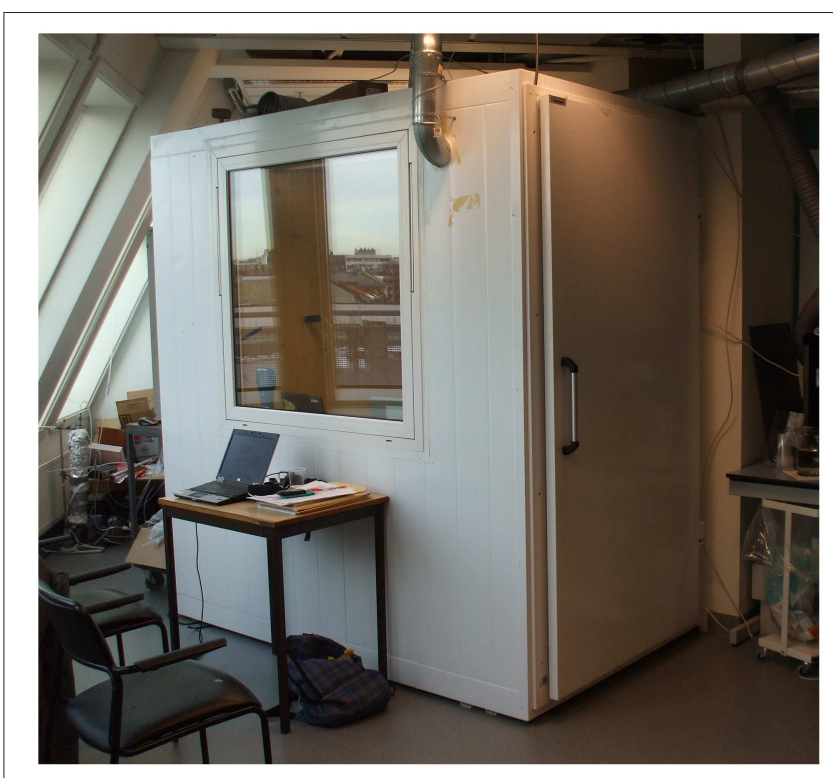

FIGURE 1 | Exterior view of the exposure chamber.

two exposures. All participants underwent both the experimental and the control exposure. Half of the group, in random order, were subjected to the experimental exposure first, while the other half were subjected to the control exposure first. The randomization was executed according to the order in which they were recruited to the study. Every second participant was allocated to the control or experimental exposure. Neither the participants nor the research staff had any knowledge of which type of exposure was applied. A carryover effect was considered and the acute effects on the respiratory and general system from the first exposure were judged to have disappeared at the time of the subsequent exposure.

In test-retest neurobehavioral studies, the challenge of the immediate practice effect (i.e., the beneficial effect of repeated neuropsychological testing on performance) must be considered (McCaffrey et al., 2000). Since the test order could influence the practice effect, we chose to include the test sequence number as a variable in the analyses (Bast-Pettersen et al., 2015). In addition, our crossover $\mathrm{AB} / \mathrm{BA}$ design enabled the comparison of test performance before/after exposure in the group exposed to pine first with the test performance in the group exposed to spruce first, provided the two subgroups were otherwise comparable regarding general performance and demographic variables. Measurements of lung function may differ between genders and a difference in these measurements between the two tests may be a result of this if there is a gender imbalance between the participants in the first and the second exposure groups.

\section{Exposure Protocol and Characterization}

The study was conducted in Oslo, Norway, in February 2013. The experimental sessions were conducted in an exposure chamber specifically designed for this purpose. The chamber was located at Oslo and Akershus University College (currently Oslo Metropolitan University), in the center of Oslo. The chamber, see Figure 1, measured $400 \mathrm{~cm}$ by $300 \mathrm{~cm}$ (floor) and the height to 
the ceiling was $240 \mathrm{~cm}$. The inside of the chamber was covered with interior paneling from Norway spruce (Picea abies). Each panel was deliberately sourced from aged low emitting panels. The floor was covered with standard vinyl flooring material. The chamber was equipped with a table and two chairs, and two Internet-connected portable computers were placed on the table. Over the table, there was a window $(100 \mathrm{~cm}$ by $120 \mathrm{~cm})$, which enabled the participants to see out of the chamber and allowed the research staff to visually survey the state of the participants. The chamber was located inside a heated and cooled building, with all external surfaces of the chamber surrounded by roomtemperature air. Changes in daylight or the view to the outdoors were not factors in this research. All measurements were collected before the pollen season. Ozone was supplied via the outdoor ventilated air. The median outdoor ozone concentration was $23 \mu \mathrm{g} / \mathrm{m}^{3}$ (13 ppb) (minimum concentration $5 \mu \mathrm{g} / \mathrm{m}^{3}$ and maximum concentration $69 \mu \mathrm{g} / \mathrm{m}^{3}$ ). The minimum, median and maximum variation in outdoor temperature and $\mathrm{RH}$ were -9.0 , -3.5 and $+1.5^{\circ} \mathrm{C}$ and 61,76 and $96 \%$, respectively.

The chamber had a tight envelope, including a door with an airtight seal. The chamber was positively pressurized relative to the surrounding space. A small heating, ventilation and airconditioning system served the chamber, providing thermally conditioned air, filtered via an F7 filter. The chamber was divided into two parts: a larger part where the participants were located and a narrow cavity in the back where pine wood was placed in the experimental setting and which was kept empty in the control setting. The total area of the pine wood was about $39 \mathrm{~m}^{2}$. Air from the ventilation system came into the lower part of the small part of the chamber and rose up beside the pine wood. At the top of the small part of the chamber, the air moved into the larger part of the chamber with the participants. This set-up was described in more detail by Nore et al. (2017). The outdoor air supply rate was maintained at a constant level.

Indoor environment parameters, temperature, $\mathrm{CO}_{2}$ and $\mathrm{RH}$ were continuously measured in real time with a Q-Trak 7565 indoor air quality monitor. Before participants entered the chamber, the chamber temperature and $\mathrm{RH}$ values were established at target values of $20.0^{\circ} \mathrm{C}$ and $15 \%$. The mean concentration of $\mathrm{CO}_{2}$ inside the chamber in each session varied between 420 and $533 \mathrm{ppm}$. The corresponding values of temperature and $\mathrm{RH}$ were $21.5-23.7^{\circ} \mathrm{C}$ and $12.0-24.2 \%$, respectively. Measurements of both indoor climate parameters and VOCs were conducted at the level of the participants' faces. The participants were dressed in their own clothes adapted for use in indoor environments. The subjects were acclimatized before exposure by being in the building for a minimum of $1 \mathrm{~h}$ before the start of the exposure.

\section{Measurement of VOCs}

A proton-transfer-reaction time-of-flight mass spectrometer (PTR-TOF 8000; IONICON Analytik GmbH, Innsbruck, Austria) was used for the online monitoring of VOCs in the exposure chamber. The analyzer was operated under standard conditions (drift-tube temperature: $60^{\circ} \mathrm{C}$, drift-tube pressure: 2.3 mbar, drift-tube voltage: $550 \mathrm{~V}$ ) and was connected to the chamber via a short inlet tube (material: Teflon ${ }^{\circledR}$ PFA, length:
$115 \mathrm{~cm}$, inner diameter: $1.57 \mathrm{~mm}$, temperature: $60^{\circ} \mathrm{C}$, flow: $300 \mathrm{ml} \mathrm{min.}^{-1}$ ). Mass spectra were recorded in the $\mathrm{m} / \mathrm{z}=10-235$ range. The PTR-TOF Data Analyzer, version 3.32 was used for data analysis. The instrument was calibrated for methanol, acetaldehyde, acetone and monoterpenes using a dynamically diluted gaseous reference standard (Apel Riemer Environmental Inc., Miami, USA). The response factors for formic acid and acetic acid were calculated using ion-molecule collision theory. All other signals were quantified as acetone-equivalents, i.e., the response factor of acetone was used to convert ion count rates into concentrations. The TVOC is the sum of these quantified ion signals. The exposure was measured continuously during each session with participants inside the chamber. In the control sessions, values were measured 17 times, while in the experimental sessions they were measured 16 times.

\section{The Participants}

Participants were recruited primarily from a population of university students, with each participant at least 18 years old. Initially, 32 participants were scheduled to be subjected to the two exposure situations. The participants had no clinical diseases or severe clinical allergies. Two participants did not attend, therefore, a total of 30 participants completed both control and experimental exposure sessions. Among the 30 participants, 17 were men and 13 were women. They were all young adults; 25 participants were 20-29 years old and five were 30-40 years old. The participants were all non-smokers and did not use smokeless tobacco, but two were former smokers and four participants had previously used smokeless tobacco on a regular basis. Two participants had previously suffered from moderate allergic symptoms. The participants reported the following moderate symptoms/diseases during the previous 6 months: five reported dry eyes, four reported upper respiratory tract infections, four had eczema, three had watery eyes, none had asthma and no participants reported migraines.

\section{Health Effects Monitoring}

All health measurements were recorded before and after the exposure for both the control and the experimental exposure. The same researchers carried out the pre- and post-exposure health effects measurements. Self-reported health symptoms involving the skin or mucous membranes, together with general symptoms, were collected using a modified version of the Swedish Indoor Air Questionnaire used in large cross-sectional studies (Eriksson and Stenberg, 2006) and intervention studies (Skulberg et al., 2004). The modification was a change in recall time. Possible responses are: $0=$ no symptoms, $1=$ symptoms sometimes and $2=$ symptoms most of the exposure time. The values from each question were summarized to two indices with possible values from zero to eight or ten: (1) a mucosal membrane index (irritation of nose, throat, eyes, or cough); and (2) a general symptom index (fatigue, heavy-headed, headache, dizziness, or concentration problems).

During the exposures, the participants were asked about their opinion on odor intensity and how they perceived the odor, this was reported on Likert-type seven point scales [e.g., no intensity (1) to very intense (7) and very unpleasant (1) to very 
pleasant (7)]. Possible differences between the two exposures were analyzed with a one-way ANOVA test.

Lung function was measured using a Micro Medical Spiro USB Spirometer with Spida 5 software (Micro Medical Ltd, Kent, UK). The forced exhaled volume after one second (FEV1) was used to measure possible obstruction symptoms. The participants conducted the lung function tests at least three times before and after the stay in the chamber, until two equal curves were recorded.

Two computerized psychological behavior tests from the Neurobehavioral Evaluation System (NES2) test battery were selected (Proctor et al., 2000): a simple reaction time (SRT) measurement and a color-word test (CWT). In the SRT test, the subject presses a button as quickly as possible each time a large square appears on a screen. The inter-trial interval is varied randomly to reduce the effects of stimulus anticipation. Individual reaction-time latencies are recorded. The simple reaction time test has been used in studies of divers and the results of these tests remained stable over a 12-year period (BastPettersen et al., 2015). The CWT is based on a modification of the Stroop effect, requiring a response to one of two competing aspects of the same stimulus, while simultaneously inhibiting the response to the other aspect (Stroop, 1935; Scarpina and Tagini, 2017). The words "red," "blue," "green," or "yellow" are flashed briefly onto a computer screen, one at a time, each in one of the four colors, with the written color name and the actual color of the word being uncorrelated. The subject responds by pressing a button as quickly as possible only when a word is presented in the color that it represents, i.e., when the color and the word are congruent. The latencies for all critical stimuli, as well as the number of non-responses and false-positive responses, are recorded.

Participants with a serious color-vision deficiency should not be included in the CWT test, since red-green color discrimination is necessary for optimal test performance. Accordingly, during the first test, before the exposure, color vision was tested using the Ishihara test with 25 plates (Kanehara Shuppan Co., Ltd., Tokyo, Japan). In a study by (Birch, 1997), the Ishihara plates were recommended for screening red-green color-vision defects. The total test time was approximately $15 \mathrm{~min}$ and the same computer was used before and after treatment.

A NIOX MINO ${ }^{\circledR}$ unit (Aerocrine, Sweden) (Alving et al., 2006; Menzies et al., 2007) was used to measure the exhaled nitric oxide (FeNO) from the airways. At least three measurements were performed before and after the exposure, in accordance with the recommendations of the European Respiratory Society (Dweik et al., 2011). The difference between the before and after measurements was used in the analyses. This measurement was used to detect eosinophilic airway inflammation.

During the performance of computer tasks inside the chamber, blinking frequencies were counted for $5 \mathrm{~min}$. The count was performed twice: the first time $10 \mathrm{~min}$ after the start of the tasks and the second time $110 \mathrm{~min}$ after the start of the tasks. The same researchers counted the blinking frequencies. Counts of blinking frequencies have been used in other experimental studies (Klenø and Wolkoff, 2004) as an indicator of irritation of the trigeminal nerve.
TABLE 1 | VOC exposure during control and experimental treatment.

\begin{tabular}{lcc}
\hline Exposure (ppb) & $\begin{array}{c}\text { Spruce (control } \\
\text { exposure) }\end{array}$ & $\begin{array}{c}\text { Pine (experimental } \\
\text { exposure) }\end{array}$ \\
\cline { 2 - 3 } & $\begin{array}{c}\text { Mean } \\
\text { (Minimum-Maximum) } \\
\text { of the medians } \mathbf{N}^{*}=\mathbf{1 7}\end{array}$ & $\begin{array}{c}\text { Mean } \\
\text { (Minimum-Maximum) } \\
\text { of the medians } \mathbf{N}^{*}=\mathbf{1 6}\end{array}$ \\
\hline Methanol & $7(6-12)$ & $31(20-42)$ \\
Acetaldehyde & $2(1-4)$ & $8(6-10)$ \\
Formic Acid & $2(1-2)$ & $11(6-14)$ \\
Acetone/Propanal & $5(3-11)$ & $14(10-20)$ \\
Acetic Acid & $4(2-8)$ & $14(7-20)$ \\
Monoterpenes & $1(1-3)$ & $172(134-202)$ \\
TVOC & $35(26-46)$ & $288(226-341)$
\end{tabular}

*Number of measured exposure sessions.

\section{Statistical Methods}

The statistical analysis was performed using IBM SPSS Statistics for Windows, version 24 (IBM Corp., Armonk, NY). A repeated measures ANOVA enables the overall differences between related means (within-subjects effects) to be tested as well as comparing the groups of respondents (between-subjects effects) (Scheiner and Gurevitch, 2001). In the current study, the between-subjects categories were determined by the subject's exposure (pine vs. spruce), in addition to the test order. A repeated measures ANOVA also enables the pattern of response of the within-subject factor to be analyzed. The interaction effects between "time" and "TVOC exposure level" and between "time" and "test order" were also evaluated.

\section{Ethics}

The study protocol and the informed consent procedures were approved by the Norwegian Regional Ethics Committee (REK case ref. 2012/974-1). Their approval was based on international conventions such as the Declaration of Helsinki. All participants provided written informed consent before participation. The participants were guided closely throughout the exposure time. Participants were entitled to withdraw their consent during the study. Scheduled participants were provided with a small amount of financial compensation for their time.

\section{RESULTS}

Table 1 shows the means of the median, minimum and maximum values of the measured concentrations of monoterpenes, methanol, acetone/propanal, acetaldehyde, formic acid, acetic acid and TVOC.

The single VOCs $\alpha$-pinene and $\Delta^{3}$-carene were the dominant VOCs among the monoterpenes. The mean exposure concentration from these six subgroups in the experimental intervention group was $250 \mathrm{ppb}\left(1,287 \mu \mathrm{g} / \mathrm{m}^{3}\right)$, while the corresponding number for the control group was $20 \mathrm{ppb}$ (43 $\left.\mu \mathrm{g} / \mathrm{m}^{3}\right)$. The mean TVOC values with a $95 \%$ confidence interval (95\% CI) for the two settings were: experimental exposure 288 ppb (266-311) and control exposure 35 ppb (32-38). 
TABLE 2 | The means of change (after-before) and difference in the analyzed parameters after exposure to VOCs of spruce and pine.

\begin{tabular}{|c|c|c|c|c|}
\hline Symptoms & Variable & $\begin{array}{l}\text { Spruce (control } \\
\text { exposure) }\end{array}$ & $\begin{array}{c}\text { Pine (experimental } \\
\text { exposure) }\end{array}$ & $\begin{array}{c}\text { Difference } \\
\text { (pine-spruce) }\end{array}$ \\
\hline \multirow{4}{*}{$\begin{array}{l}\text { Irritation symptoms and } \\
\text { measurements }\end{array}$} & Questionnaire & -0.02 & 0.08 & 0.10 \\
\hline & FEV1 (ml) & 2.8 & 0.3 & -2.5 \\
\hline & FeNO (ppb) & 0 & 1 & 1 \\
\hline & Eye blinking frequency (N) & 13.8 & 4.4 & -9.4 \\
\hline \multirow{5}{*}{$\begin{array}{l}\text { General symptoms and } \\
\text { measurements }\end{array}$} & Questionnaire & -0.03 & -0.17 & -0.14 \\
\hline & Reaction time test (ms) & 8.4 & 8.7 & -0.3 \\
\hline & Color-Word test-time (ms) & -12.0 & -10.6 & 1.4 \\
\hline & Color-Word test-False positive $(\mathrm{N})$ & -0.1 & -0.7 & -0.6 \\
\hline & Color-Word test-Non-reaction (N) & -0.5 & -1.0 & -0.5 \\
\hline
\end{tabular}

TABLE 3 | Associations between exposure to VOCs from spruce and pine and measurements of irritation and general symptoms analyzed with a repeated measures ANOVA-between-subjects effect.

\begin{tabular}{|c|c|c|c|c|c|}
\hline Symptoms & Variable & & $F$-value & Degrees of freedom & $p$-value \\
\hline \multirow{8}{*}{$\begin{array}{l}\text { Irritation symptoms } \\
\text { and measurements }\end{array}$} & Questionnaire & VOC & 0.143 & $1(55)$ & 0.707 \\
\hline & & Test order & 1.583 & $1(55)$ & 0.214 \\
\hline & FEV1 & VOC & 0.001 & $1(51)$ & 0.975 \\
\hline & & Test order & 4.975 & $1(51)$ & 0.030 \\
\hline & FeNO & VOC & 0.001 & $1(57)$ & 0.980 \\
\hline & & Test order & 1.623 & $1(57)$ & 0.208 \\
\hline & Eye blinking frequency & VOC & 1.373 & $1(57)$ & 0.246 \\
\hline & & Test order & 1.555 & $1(57)$ & 0.218 \\
\hline \multirow{10}{*}{$\begin{array}{l}\text { General symptoms } \\
\text { and measurements }\end{array}$} & Questionnaire & VOC & 0.149 & $1(55)$ & 0.701 \\
\hline & & Test order & 4.559 & $1(55)$ & 0.037 \\
\hline & Reaction test-time & VOC & 0.162 & $1(57)$ & 0.689 \\
\hline & & Test order & 0.953 & $1(57)$ & 0.333 \\
\hline & Color-word test-time & VOC & 1.138 & $1(57)$ & 0.291 \\
\hline & & Test order & 2.915 & $1(57)$ & 0.093 \\
\hline & Color-word test-false positive & VOC & 0.270 & $1(57)$ & 0.869 \\
\hline & & Test order & 11.047 & $1(57)$ & 0.002 \\
\hline & Color-word test-non-reaction & VOC & 0.760 & $1(57)$ & 0.727 \\
\hline & & Test order & 26.860 & $1(57)$ & 0.041 \\
\hline
\end{tabular}

Bold $=p<0.05$

The perceived odor inside the chamber was considered to be statistically significantly more intense when exposed to pine in comparison to spruce (mean score pine $=4.3$ and mean score spruce $=3.4, p$-value $=0.001$ ). However, there was no statistically significant difference in the perception of whether the odor was unpleasant or pleasant (mean score pine $=4.4$ and mean score spruce $=4.3, p$-value $=0.75$ ).

Minor differences in the means of changes between the experimental exposure and the control exposure were revealed, in relation to both irritation symptoms and general symptoms (Table 2). The differences were not statistically significant. The objective measurements effects showed some differences: the control group had a slight increase of FEV1, the experimental exposure resulted in a weak increase in $\mathrm{FeNO}$ and both groups increased their eye-blinking frequencies during exposure. Regarding the neuropsychological SRT test, reaction time increased slightly (by $8 \mathrm{~ms}$ ) during the last exposure, compared with the first exposure. For the CWT, all groups improved their reaction time (by approximately $9 \mathrm{~ms}$ ) and completed the test with fewer errors immediately after exposure, compared to before exposure.

Between-subjects effects examine differences between groups of individuals. The two different groups in Table 3 were those exposed to VOCs from pine and those exposed to VOCs from spruce, for a given test order. The analyses on VOCs (subjective questionnaire and measured objective tests) were not statistically significantly different between the experimental exposure and the control exposure.

The ordering of the exposure, c.f. either spruce first or pine first, was statistically significant in four of the analyses: the lung function test FEV1, the general symptoms from the questionnaire, the number of false positives in the CWT and the number of non-reactions in the CWT. 
TABLE 4 | Associations between exposure to VOCs from spruce and pine and measurements of irritation and general symptoms analyzed with a repeated measures ANOVA-within-subjects effects.

\begin{tabular}{|c|c|c|c|c|c|}
\hline Symptoms & Variable & & $F$-value & Degrees of freedom & $p$-value \\
\hline \multirow{12}{*}{$\begin{array}{l}\text { Irritation symptoms } \\
\text { and measurements }\end{array}$} & \multirow[t]{3}{*}{ Questionnaire } & Time & 0.409 & $1(55)$ & 0.525 \\
\hline & & Time*VOC & 0.435 & $1(55)$ & 0.513 \\
\hline & & Time ${ }^{\star}$ Test order & 7.223 & $1(55)$ & 0.010 \\
\hline & \multirow[t]{3}{*}{ FEV1 } & Time & 1.661 & $1(51)$ & 0.203 \\
\hline & & Time*VOC & 0.917 & $1(51)$ & 0.343 \\
\hline & & Time ${ }^{\star}$ Test order & 0.250 & $1(51$ & 0.619 \\
\hline & \multirow[t]{3}{*}{ FeNO } & Time & 3.565 & $1(57)$ & 0.064 \\
\hline & & Time*VOC & 1.098 & $1(57)$ & 0.299 \\
\hline & & Time ${ }^{\star}$ Test order & 3.331 & $1(57$ & 0.073 \\
\hline & \multirow[t]{3}{*}{ Eye blinking frequency } & Time & 5.031 & $1(57)$ & 0.029 \\
\hline & & Time*VOC & 1.159 & $1(57)$ & 0.286 \\
\hline & & Time ${ }^{*}$ Test order & 0.044 & $1(57$ & 0.834 \\
\hline \multirow{15}{*}{$\begin{array}{l}\text { General symptoms } \\
\text { and measurements }\end{array}$} & \multirow[t]{3}{*}{ Questionnaire } & Time & 4.1867 & $1(55)$ & 0.046 \\
\hline & & Time*VOC & 2.932 & $1(55)$ & 0.093 \\
\hline & & Time ${ }^{\star}$ Test order & 0.035 & $1(55)$ & 0.852 \\
\hline & \multirow[t]{3}{*}{ Reaction test-time } & Time & 6.161 & $1(57)$ & 0.016 \\
\hline & & Time*VOC & 0.043 & $1(57)$ & 0.837 \\
\hline & & Time ${ }^{\star}$ Test order & 0.264 & $1(57$ & 0.609 \\
\hline & \multirow[t]{3}{*}{ Color-word test-time } & Time & 7.235 & $1(57)$ & 0.009 \\
\hline & & Time*VOC & 0.970 & $1(57)$ & 0.757 \\
\hline & & Time ${ }^{\star}$ Test order & 1.210 & $1(57$ & 0.276 \\
\hline & \multirow{3}{*}{$\begin{array}{l}\text { Color-word test-number of } \\
\text { false positives }\end{array}$} & Time & 4.120 & $1(57)$ & 0.047 \\
\hline & & Time*VOC & 1.699 & $1(57)$ & 0.198 \\
\hline & & Time ${ }^{\star}$ Test order & 6.601 & $1(57$ & 0.130 \\
\hline & \multirow{3}{*}{$\begin{array}{l}\text { Color-word test-number of } \\
\text { non-reactions }\end{array}$} & Time & 10.149 & $1(57)$ & 0.002 \\
\hline & & Time*VOC & 0.463 & $1(57)$ & 0.499 \\
\hline & & Time*Test order & 4.434 & $1(57$ & 0.040 \\
\hline
\end{tabular}

Bold $=p<0.05$.

Table 4 shows the within-subjects effects in our population. These analyses represent the variability of time, the time interaction with VOCs and the time interaction with the test order.

No statistically significant differences were revealed in the analysis of the possible interaction between time and VOCs as a within-subjects effect. However, six tests were statistically significant for the time alone. Simply being in the chamber for $2 \mathrm{~h}$ had an effect on the participants. The interaction between time and the test order was statistically significant twice, for the questionnaire on general symptoms and for the CWT test non-responses.

\section{DISCUSSION}

This study was a controlled, double-blinded, crossover, experimental study, considering the health effects of exposure to VOCs from a high-emitting wood species, Scots pine, compared to the health effects of exposure to VOCs from a low-emitting wood species, Norway spruce. The study was conducted with a statistically significant difference in the exposure to VOCs between the experimental (pine) and the control (spruce) treatments. The results regarding health effects (subjective and objective symptoms of eyes, upper respiratory airways and cognitive function) showed no statistically significant difference between the two experimental conditions. Exposure to VOCs from pine had no adverse health effects on the participants compared with exposure to VOCs from spruce. This may support the conclusions of Wolkoff and Nielsen (2017), that the maximum indoor concentrations of common VOCs are below the threshold for sensory irritation and for pulmonary or nervous system toxic effects. Odor perception or distractive effects are considered a more probable mechanism of altered task performance related to the differential exposure conditions.

Participants were informed of the general purpose of the study but had no information on the exposure to the two different softwoods. The research staff did not know the type of exposure. Therefore, our assessment is that this study was a real double-blinded study. One possible problem with the blinding of the exposure was that pine has a stronger odor than spruce, thus, the subjects can in principle distinguish between different set-ups. However, despite this difference and taking into consideration that spruce and pine are both very common 
building materials in Norway, it is reasonable to believe that most people and in particular the rather urban participants recruited for participation in this study, do not have sufficiently specific knowledge of the odor from either spruce or fresh pine to differentiate clearly between the exposure situations. Furthermore, the fact that the exposures took place on different days makes it difficult to compare odor between exposures. It is also worth noting that the participants did not perceive the odor from pine to be more unpleasant than spruce despite the more intense odor.

The test order, spruce or pine first, was statistically significant in the between-subjects analysis in the CWT. The means of the numbers of errors (both false positives and non-reactions) for both groups were reduced after exposure, compared to before exposure. The numbers of errors before exposure in the second exposure period were higher and the improvements were greater, compared with exposure for the first time (not shown in the tables). This may be a "regression to the mean effect," which has previously been demonstrated in intervention studies (Skulberg et al., 2001, 2004) on indoor environments, or it may be a learning effect (McCaffrey et al., 2000).

Practice effects resulting from repeated testing seem to have had only a minor or temporary impact on performance in this study. In line with the observed stable SRT reaction times of approximately $220 \mathrm{~ms}$, both as a baseline and at sixand 12-year follow-up (Bast-Pettersen et al., 2015), the mean pre-exposure reaction times in our study were comparable for the total group for both test periods (approximately $260 \mathrm{~ms}$ for SRT and $586 / 583 \mathrm{~ms}$ for CWT). While the postexposure SRT was actually slightly longer (approximately $268 \mathrm{~ms}$ ) than pre-exposure SRT in both test periods, which does not support the possibility of a practice effect for this test, the reduction in reaction time for the more cognitively demanding CWT test $(572 / 574 \mathrm{~ms})$ may indicate a possible temporary practice effect when the inter-test interval is as short as the exposure period. However, such an interpretation must be balanced against the precision measures of false positive responses and non-responses.

The test order was also statistically significant in two other analyses: the measurement of FEV1 and the questionnaire on general symptoms. This may be explained by the different proportion of women in Group 1 (15\%) compared to Group 2 (65\%). Women have a smaller lung volume than men and women reported more general symptoms than men in indoor environment studies (Skyberg et al., 2003).

Statistically significant within-subjects effects were revealed for "time" in several analyses. The SRT test showed deteriorated results, while the CWT showed improved results after exposure, compared to before exposure. In addition, eye blinking increased during exposure for both groups and the general symptoms were slightly exacerbated. These effects may be explained as reactions to being in the chamber for $2 \mathrm{~h}$. A possible explanation of this finding may be the low RH in the chamber. Low RH could have altered the precorneal tear film and thus influenced participants at both exposure situations. The thinning of the precorneal tear film may cause eye complaints. Low RH may exacerbate the effect of sensory irritants on the eye (Wolkoff et al., 2005). Other factors, such as high room temperature, can lead to a decrease in blinking and demanding tasks may also alter the precorneal tear film. In a laboratory experiment by Nøjgaard et al. (2005) ten males were exposed to limonene oxidation products and a terpene oxidation product. During the exposure, the $\mathrm{RH}$ was $20 \%$. The mean blinking frequency increased significantly during the exposure compared to exposure to clean air. The lowest observed effect levels were found with mixtures of $92 \mathrm{ppb}$ limonene and $101 \mathrm{ppb}$ ozone. In this study, the RH varied from 12 to $24 \%$, the mean outdoor concentration of ozone was $13 \mathrm{ppb}$ and the mean concentration of the measured VOCs from pine was $288 \mathrm{ppb}$.

The outdoor ozone concentration will usually be in the 10-100 $\mathrm{ppb}$ range. The concentration of ozone in indoor air depends on different factors (e.g., outdoor ozone concentration, air exchange rates, surface removal rates and reactions between ozone and other chemicals) (Weschler, 2000). In a study by Nørgaard et al. (2014), different VOCs and their reaction products from consumer products were measured with and without ozone. The concentrations of ozone were $50 \mathrm{ppb}$ and $5 \mathrm{ppb}$. In this study, no indoor concentrations of ozone, formaldehyde or SOA were measured during the exposure. However, the ozone concentration could not be higher than the outdoor level. In a follow-up experiment (not published) with the same experimental set-up, the measured concentration of ozone was always zero. Ozone was probably titrated away by the terpenes. No SOA was formed in the chamber due to low ozone levels. A similar experimental study was conducted by Gminski et al. (2011b). The participants were exposed to VOC concentrations up to $13 \mathrm{mg} / \mathrm{m}^{3}$, but no adverse health effects were recorded. The results from this experiment are in agreement with the results of Gminski et al. (2011b) as well as with the results of Fiedler et al. (2005) and Laumbach et al. (2005). VOCs from indoor air with and without ozone were measured and the health outcomes of lung function, nasal inflammatory markers and neurobehavioral effects were recorded. No associations between exposure and lung function, nasal inflammation or cognitive function were found. These experiments lead to the conclusion that no negative health effects, except possible odor effects, can be expected during exposure to high VOC concentrations from wood. The participants in this study come from a country where wood has been used as a building material for centuries. The odor from the wood may then be judged as natural and without negative influence.

\section{CONCLUSIONS}

The main aim of this study was to examine the health effects associated with exposure to VOCs from pine, compared to the health effects associated with exposure to VOCs from spruce as a control group. In relation to respiratory irritation, general health effects and neuropsychological tests, the results showed no statistically significant differences between the two different exposures. Exposure to VOCs from pine had no inflammatory reaction effects, no sensory irritation effects or no negative 
performance effects on the participants compared with VOCs from spruce.

\section{FUTURE RESEARCH}

In the present study, the focus was investigating exposure to VOCs as a risk factor for health effects. In some other scientific studies, the focus has been on the health promotion effects of exposure. In an experimental study by Ikei et al. (2016), olfactory exposure to $\alpha$-pinene was significantly associated with decreased heart rate. The measurements indicated that the parasympathetic nervous system was involved in this physiological relaxation. Furthermore, $\alpha$-pinene had a documented anti-inflammatory effect on mice cells (Kim et al., 2015). These studies used oils containing $\alpha$-pinene. Some animal studies have revealed an anti-inflammatory effect from the terpene limonene on allergic inflammation (Bibi et al., 2015; Hansen et al., 2016) and the authors discussed whether ozone itself was an inflammatory mediator and the possibility that reactions between limonene and ozone could reduce the concentration of ozone and reduce the inflammatory reactions. In an experimental study by Fadeyi et al. (2015), asthmatic and non-asthmatic participants were exposed to a mixture of limonene and ozone. The asthmatic group had statistically significantly less nose and throat irritation than the non-asthmatic group. There were no statistically significant differences regarding eye irritation. As such, if exposure to $\alpha$ pinene in indoor air has a clinical anti-inflammatory effect, it may reduce the number and the morbidity of non-infectious respiratory diseases among adolescents. Our knowledge of the possible positive human health effects associated with exposure to $\alpha$-pinene is weak and therefore its potential effects should be further explored.

\section{DATA AVAILABILITY}

The datasets generated for this study are available on request to the corresponding author.

\section{REFERENCES}

Allen, J. G., MacNaughton, P., Satish, U., Santanam, S., Vallarino, J., and Spengler, J. D. (2016). Associations of cognitive function scores with carbon dioxide, ventilation, and volatile organic compound exposures in office workers: a controlled exposure study of green and conventional office environments. Environ. Health Perspect. 124, 805-812. doi: 10.1289/ehp.1510037

Alving, K., Janson, C., and Nordvall, L. (2006). Performance of a new hand-held device for exhaled nitric oxide measurement in adults and children. Respir. Res. 7:67. doi: 10.1186/1465-9921-7-67

Andersson, M. A., Nikulin, M., Köljalg, U., Andersson, M. C., Rainey, F., Reijula, K., et al. (1997). Bacteria, molds, and toxins in water-damaged building materials. Appl. Environ. Microbiol. 63, 387-393.

Bast-Pettersen, R., Skare, Ø., Nordby, K. C., and Skogstad, M. (2015). A twelve-year longitudinal study of neuropsychological function in nonsaturation professional divers. Int. Arch. Occup. Environ. Health 88, 669-682. doi: 10.1007/s00420-014-0991-0

Bibi, H., Reany, O., Waisman, D., and Keinan, E. (2015). Prophylactic treatment of asthma by an ozone scavenger in a mouse model. Bioorg. Med. Chem. Lett. 25, 342-346. doi: 10.1016/j.bmcl.2014.11.035

\section{ETHICS STATEMENT}

The study protocol and the informed consent procedures was approved by the Norwegian Regional Ethics Committee (REK case ref. 2012/974-1). All participants provided written informed consent before participation. The participants were guided closely through all the exposure time. Participants were entitled to withdraw their consent during the study. Scheduled participants were provided a small amount of financial compensation for their time.

\section{AUTHOR CONTRIBUTIONS}

KS and AN designed the study. LG was responsible for the neuropsychological tests. AW was responsible for the VOC measurements. All authors carried out the experiments. Statistical analyses were conducted by KS and AN. KS and AN prepared the first draft and all authors contributed to the preparation of the manuscript.

\section{ACKNOWLEDGMENTS}

This study was carried out as part of the Wood-Energy, Emissions, Experience (WEEE) research study, the principal investigator of which is Kristine Nore of the Norwegian Institute of Wood Technology. The authors gratefully acknowledge the financing authorities of the project, the Norwegian Research Council (Grant Number: 216404/010) and supporting industry partners: Norsk Laft, Splitkon AS and Södra Interiör AS.

We thank Professor Oddbjørn Sjøvold for facilitating the study. We thank Ulrike Heinemann, Christine Aronsen and Nils Otto Ledermann for their support with the design of the chamber and the logistics in relation to participants and for conducting the health measurements. We thank Stephan Langebner and Philipp Eichler for their support with the PTR-ToF-MS measurements and data analyses.

Birch, J. (1997). Efficiency of the Ishihara test for identifying redgreen colour deficiency. Ophthalmic. Physiol. Opt. 17, 403-408. doi: 10.1111/j.1475-1313.1997.tb00072.x

Brüning, T., Bartsch, R., Bolt, H. M., Desel, H., Drexler, H., Gundert-Remy, U., et al. (2014). Sensory irritation as a basis for setting occupational exposure limits. Arch. Toxicol. 88, 1855-1879. doi: 10.1007/s00204-0141346-z

CEN (2017). EN 16516 Construction products: Assessment of Release of Dangerous Substances - Determination of Emissions into Indoor Air. Brussels: European Committee for Standardization.

Dodoo, A., Gustavsson, L., and Sathre, R. (2009). Carbon implications of end-oflife management of building materials. Resour. Conserv. Recycling 53, 276-286. doi: 10.1016/j.resconrec.2008.12.007

Dweik, R. A., Boggs, P. B., Erzurum, S. C., Irvin, C. G., Leigh, M. W., Lundberg, J. O., et al. (2011). An official ATS clinical practice guideline: interpretation of exhaled nitric oxide levels (FeNO) for clinical applications. Am. J. Respir. Crit. Care Med. 184, 602-615. doi: 10.1164/rccm.9120-11ST

ECA (2013). Report No 29. EUR 26168 EN. Harmonisation Framework for Health Based Evaluation of Indoor Emissions From Construction Products in the European Union using the EU-LCI concept. Luxembourg: ECA. 
Eriksson, N. M., and Stenberg, B. G. (2006). Baseline prevalence of symptoms related to indoor environment. Scand. J. Public Health 34, 387-396. doi: $10.1080 / 14034940500228281$

Fadeyi, M. O., Tham, K. W., and Wu, W. Y. (2015). Impact of asthma, exposure period, and filters on human responses during exposures to ozone and its initiated chemistry products. Indoor Air 25, 512-522. doi: 10.1111/ina. 12161

Fiedler, N., Laumbach, R., Kelly-McNeil, K., Lioy, P., Fan, Z. H., Zhang, J., et al. (2005). Health effects of a mixture of indoor air volatile organics, their ozone oxidation products, and stress. Environ. Health Perspect. 113, 1542-1548. doi: 10.1289/ehp. 8132

Glas, B., Stenberg, B., Stenlund, H., and Sunesson, A. L. (2015). Exposure to formaldehyde, nitrogen dioxide, ozone, and terpenes among office workers and associations with reported symptoms. Int. Arch. Occup. Environ. Health 88, 613-622. doi: 10.1007/s00420-014-0985-y

Glasius, M., Lahaniati, M., Calogirou, A., Di Bella, D., Jensen, N. R., Hjorth, J., et al. (2000). Carboxylic acids in secondary aerosols from oxidation of cyclic monoterpenes by ozone. Environ. Sci. Technol. 34, 1001-1010. doi: $10.1021 / \mathrm{es} 990445 \mathrm{r}$

Gminski, R., Marutzky, R., Kevekordes, S., Fuhrmann, F., Bürger, W., Hauschke, D., et al. (2011a). Chemosensory irritations and pulmonary effects of acute exposure to emissions from oriented strand board. Hum. Exp. Toxicol. 30, 1204-1221. doi: 10.1177/0960327110388537

Gminski, R., Marutzky, R., Kevekordes, S., Fuhrmann, F., Bürger, W., Hauschke, D., et al. (2011b). Sensory irritations and pulmonary effects in human volunteers following short-term exposure to pinewood emissions. J. Wood Sci. 57, 436-445. doi: 10.1007/s10086-011-1182-1

Hansen, J. S., Nørgaard, A. W., Koponen, I. K., Sørli, J. B., Paidi, M. D., Hansen, S. W. K., et al. (2016). Limonene and its ozone-initiated reaction products attenuate allergic lung inflammation in mice. J. Immunotoxicol. 13, 793-803. doi: 10.1080/1547691X.2016.1195462

Hyttinen, M., Masalin-Weijo, M., Kalliokoski, P., and Pasanen, P. (2010). Comparison of VOC emissions between air-dried and heat-treated Norway spruce (Picea abies), Scots pine (Pinus sylvesteris) and European aspen (Populus tremula) wood. Atmos. Environ. 44, 5028-5033. doi: 10.1016/j.atmosenv.2010.07.018

Ikei, H., Song, C., and Miyazaki, Y. (2016). Effects of olfactory stimulation by alpha-pinene on autonomic nervous activity. J. Wood Sci. 62, 568-572. doi: $10.1007 / \mathrm{s} 10086-016-1576-1$

Kim, D. S., Lee, H. J., Jeon, Y. D., Han, Y. H., Kee, J. Y., Kim, H. J., et al. (2015). Alpha-pinene exhibits anti-inflammatory activity through the suppression of MAPKs and the NF-kappaB pathway in mouse peritoneal macrophages. Am. J. Chin. Med. 43, 731-742. doi: 10.1142/S0192415X1 5500457

Klenø, J., and Wolkoff, P. (2004). Changes in eye blink frequency as a measure of trigeminal stimulation by exposure to limonene oxidation products, isoprene oxidation products and nitrate radicals. Int. Arch. Occup. Environ. Health 77, 235-243. doi: 10.1007/s00420-003-0502-1

Laumbach, R. J., Fiedler, N., Gardner, C. R., Laskin, D. L., Fan, Z. H., Zhang, J., et al. (2005). Nasal effects of a mixture of volatile organic compounds and their ozone oxidation products. J. Occup. Environ. Med. 47, 1182-1189. doi: $10.1097 / 01$.jom.0000183338.95778.f0

Lin, C. C., Yu, K. P., Zhao, P., and Lee, G. W. M. (2009). Evaluation of impact factors on VOC emissions and concentrations from wooden flooring based on chamber tests. Build. Environ. 44, 525-533. doi: 10.1016/j.buildenv.2008.04.015

Maula, H., Hongisto, V., Naatula, V., Haapakangas, A., and Koskela, H. (2017). The effect of low ventilation rate with elevated bioeffluent concentration on work performance, perceived indoor air quality, and health symptoms. Indoor Air 27, 1141-1153. doi: 10.1111/ina.12387

McCaffrey, R. J., Duff, K., and Westervelt, H. J. (2000). Practitioner's Guide to Evaluating Change with Intellectual Assessment Instruments. New York, NY: Springer Science+Business Media, LLC.

Menzies, D., Nair, A., and Lipworth, B. J. (2007). Portable exhaled nitric oxide measurement: comparison with the gold standard technique. Chest 131, 410-414. doi: 10.1378/chest.06-1335

Mølhave, L. (2003). Biomarkers and other substitute measures in indoor air sciences. Indoor Air 13, 369-70; discussion 373-6. doi: 10.1046/j.0905-6947.2003.00227.x
Nielsen, G. D., Larsen, S. T., Olsen, O., Løvik, M., Poulsen, L. K., Glue, C., et al. (2007). Do indoor chemicals promote development of airway allergy? Indoor Air 17, 236-255. doi: 10.1111/j.1600-0668.2006.00468.x

Nojgaard, J. K., Bilde, M., Stenby, C., Nielsen, O. J., and Wolkoff, P. (2006). The effect of nitrogen dioxide on particle formation during ozonolysis of two abundant monoterpenes indoors. Atmosp. Environ. 40, 1030-1042. doi: 10.1016/j.atmosenv.2005.11.029

Nøjgaard, J. K., Christensen, K. B., and Wolkoff, P. (2005). The effect on human eye blink frequency of exposure to limonene oxidation products and methacrolein. Toxicol. Lett. 156, 241-251. doi: 10.1016/j.toxlet.2004.11.013

Nore, K., Nyrud, A. Q., Kraniotis, D., Skulberg, K. R., Englund, F., and Aurlien, T. (2017). Moisture buffering, energy potential, and volatile organic compound emissions of wood exposed to indoor environments. Sci. Technol. Built Environ. 23, 512-521. doi: 10.1080/23744731.2017.1288503

Nørgaard, A. W., Kudal, J. D., Kofoed-Sørensen, V., Koponen, I. K., and Wolkoff, P. (2014). Ozone-initiated VOC and particle emissions from a cleaning agent and an air freshener: risk assessment of acute airway effects. Environ. Int. 68, 209-218. doi: 10.1016/j.envint.2014.03.029

Pacharra, M., Schäper, M., Kleinbeck, S., Blaszkewicz, M., Golka, K., and van Thriel, C. (2016). Neurobehavioral effects of exposure to propionic acid revisited-Does psychosocial stress interfere with distractive effects in volunteers? Neurotoxicology 55, 102-111. doi: 10.1016/j.neuro.2016. 05.019

Pommer, L., Fick, J., Nilsson, C., and Andersson, B. (2004). An experimental comparison of a kinetic model for the reaction of alpha-pinene and Delta(3)carene with ozone and nitrogen oxides. Indoor Air 14(Suppl. 8):75-83. doi: 10.1111/j.1600-0668.2004.00302.x

Proctor, S. P., Letz, R., and White, R. F. (2000). Validity of a computer-assisted neurobehavioral test battery in toxicant encephalopathy. Neurotoxicology 21, 703-714.

Risholm-Sundman, M., Lundgren, M., Vestin, E., and Herder, P. (1998). Emissions of acetic acid and other volatile organic compounds from different species of solid wood. Holz Als Roh-Und. Werkstoff 56, 125-129. doi: $10.1007 / \mathrm{s} 001070050282$

Roffael, E. (2006). Volatile organic compounds and formaldehyde in nature, wood and wood based panels. Holz Als Roh-Und. Werkstoff 64, 144-149. doi: 10.1007/s00107-005-0061-0

Roffael, E., Behn, C., and Dix, B. (2012). On the formaldehyde release of wood particles. Eur. J. Wood Wood Products 70, 911-912. doi: $10.1007 / \mathrm{s} 00107-012-0625-8$

Satish, U., Mendell, M. J., Shekhar, K., Hotchi, T., Sullivan, D., Streufert, S., et al. (2012). Is CO2 an indoor pollutant? Direct effects of low-to-moderate $\mathrm{CO} 2$ concentrations on human decision-making performance. Environ. Health. Perspect. 120, 1671-1677. doi: 10.1289/ehp.1104789

Scarpina, F., and Tagini, S. (2017). The stroop color and word test. Front. Psychol. 8:557. doi: $10.3389 /$ fpsyg.2017.00557

Scheiner, S. M., and Gurevitch, J. (2001). Design and Analysis of Ecological Experiments. 2nd ed. Oxford; New York, NY: Oxford University Press.

Seaman, V. Y., Bennett, D. H., and Cahill, T. M. (2007). Origin, occurrence, and source emission rate of acrolein in residential indoor air. Environ. Sci. Technol. 41, 6940-6946. doi: 10.1021/es0707299

Skulberg, K. R., Skyberg, K., Eduard, W., Goffeng, L. O., Vistnes, A. I., Levy, F., et al. (2001). Effects of electric field reduction in visual display units on skin symptoms. Scand. J. Work Environ. Health 27, 140-145. doi: 10.5271/sj weh.601

Skulberg, K. R., Skyberg, K., Kruse, K., Eduard, W., Djupesland, P., Levy, F., et al. (2004). The effect of cleaning on dust and the health of office workers: an intervention study. Epidemiology 15, 71-78. doi: 10.1097/01.ede.0000101020.72399.37

Skyberg, K., Skulberg, K. R., Eduard, W., Skåret, E., Levy, F., and Kjuus, H. (2003). Symptoms prevalence among office employees and associations to building characteristics. Indoor Air 13, 246-252. doi: 10.1034/j.1600-0668.2003.00 190.x

Stroop, J. R. (1935). Studies of Interference in Serial Verbal Reactions. Ph.D., George Peabody College for Teachers.

Tagiyeva, N., and Sheikh, A. (2014). Domestic exposure to volatile organic compounds in relation to asthma and allergy in children and adults. Expert Rev. Clin. Immunol. 10, 1611-1639. doi: 10.1586/1744666X.2014.972943 
Wells, J. R., Schoemaecker, C., Carslaw, N., Waring, M. S., Ham, J. E., Nelissen, I., et al. (2017). Reactive indoor air chemistry and health-A workshop summary. Int. J. Hyg. Environ. Health 220, 1222-1229. doi: 10.1016/j.ijheh.2017.09.009

Weschler, C. J. (2000). Ozone in indoor environments: concentration and chemistry. Indoor Air Int. J. Indoor Air Quality Climate 10, 269-288. doi: 10.1034/j.1600-0668.2000.010004269.x

Wolkoff, P. (2013). Indoor air pollutants in office environments: Assessment of comfort, health, and performance. Int. J. Hygiene Environ. Health 216, 371-394. doi: 10.1016/j.ijheh.2012.08.001

Wolkoff, P., Clausen, P. A., Wilkins, C. K., and Nielsen, G. D. (2000). Formation of strong airway irritants in terpene/ozone mixtures. Indoor Air 10, 82-91. doi: $10.1034 / j .1600-0668.2000 .010002082 . x$

Wolkoff, P., and Nielsen, G. D. (2017). Effects by inhalation of abundant fragrances in indoor air - An overview. Environ. Int. 101:96-107. doi: 10.1016/j.envint.2017.01.013
Wolkoff, P., Nøjgaard, J. K., Troiano, P., and Piccoli, B. (2005). Eye complaints in the office environment: precorneal tear film integrity influenced by eye blinking efficiency. Occup. Environ. Med. 62, 4-12. doi: 10.1136/oem.2004.016030

Conflict of Interest Statement: The authors declare that the research was conducted in the absence of any commercial or financial relationships that could be construed as a potential conflict of interest.

Copyright (๑) 2019 Skulberg, Nyrud, Goffeng and Wisthaler. This is an open-access article distributed under the terms of the Creative Commons Attribution License (CC $B Y)$. The use, distribution or reproduction in other forums is permitted, provided the original author(s) and the copyright owner(s) are credited and that the original publication in this journal is cited, in accordance with accepted academic practice. No use, distribution or reproduction is permitted which does not comply with these terms. 